\title{
The Difference of Hypoxia Inducible Factor $2 \alpha$ mRNA Expression in High-Grade and Low-Grade Glioma Tissue
}

\author{
Bagus Ramasha Amangku ${ }^{1}$, Syaiful Ichwan ${ }^{2}$, Septelia Inawati Wanandi ${ }^{3}$, \\ Novi Silvia Hardiany ${ }^{3}$ \\ ${ }^{1}$ Undergraduate Student of International Class Program Faculty of Medicine, Universitas Indonesia, Jakarta, Indonesia \\ ${ }^{2}$ Department of Neurosurgery Faculty of Medicine Universitas Indonesia, Cipto Mangunkusumo Hospital, \\ Jakarta, Indonesia \\ ${ }^{3}$ Department of Biochemistry and Molecular Biology Faculty of Medicine Universitas Indonesia, Jakarta, Indonesia
}

\section{ARTICLE INFO}

Received : 29 March 2019

Reviewed: 10 May 2019

Accepted : 21 May 2019

\section{Keywords:}

glioma, HIF-2 $\alpha$, hypoxia, mRNA

expression
${ }^{*}$ Corresponding author: Novi Silvia Hardiany Department of Biochemistry and Molecular Biology Faculty of Medicine Universitas Indonesia. Salemba Raya No. 6, Jakarta Pusat, Indonesia

Email: novish98@gmail.com; novi.silva@ui.ac.id

\begin{abstract}
Background: HIF-2 $\alpha$ is a transcription factor in hypoxic condition, and high expression levels of it correlate with the concepts of metastasis, therapy opposition and reduced quality of prognosis in various forms of cancerous growth. Due to the exceedingly infiltrative ability of brain glioma cells, gliomas cannot be completely deteriorated with surgery and the relapse rate is high. This study goal to identify the relative expression of HIF- $2 \alpha$ gene in the direction of glioma malignancy and its classification.
\end{abstract}

Methods: Specimens used in this research comprise of 20 glioma samples obtained from glioma patients in Cipto Mangunkusumo Hospital. Relative expression of HIF-2 $\alpha$ was measured by utilizing quantitative Real Time-Polymerase Chain Reaction (RT-PCR). Cycle threshold (CT) values were achieved correlated with the amplified DNA, and then the relative expression was attained by using Livak method of calculation.

Results: The results produced a greater average of relative expression of HIF-2 $\alpha$ in the grade III and IV types $(18.64 ; n=7)$ rather than in the lower grades $(5.68 ; n=13)$. However, the data is statistically inconsequential.

Conclusions: High-grade glioma tends to express HIF-2 $\alpha$ mRNA higher compared to the lower grade. Therefore, it is possible to use HIF-2 $\alpha$ as a prognostic marker for gliomadiagnosed patients, although additional experiments need to be performed to strengthen these facts.

\section{INTRODUCTION}

Brain tumors occurrence can be categorized as common, as it is also threatening represented by $12-15$ months median survival time in its most detrimental stage (grade IV) despite the comprehensive treatment delivered in the hospital [1]. Gliomas, meningiomas, and malignant growth from systemic carcinoma are the most frequent cases [2]. Gliomas contribute as the most frequent malignant tumor in the central nervous system, epitomized by the fact that $81 \%$ of malignant brain tumor cases are gliomas [3]. The World Health Organization (WHO) has made a classification that categorizes glioma according to their histological appearances and the type of glial cells that arise to malignancy. The classification divided gliomas into 4 gradings, which are low-grade lesions (I-II) to high-grade
(III-IV) malignancies. Glioblastoma multiforme (GBM) is a term that is used for grade IV glioma. It is heavily aggressive and the most frequent kind compared to other glioma types, which constitutes around $60-70 \%$ cases of malignant gliomas $[1,4]$.

Management for this type of primary brain cancer consists of surgery and chemoradiation. However, due to its exceedingly infiltrative ability, gliomas cannot be completely deteriorated with surgery alone. The operation may detach the proportion of the tumor, but the remaining cancer cells in the periphery can generate relapses [5]. In addition to that, preceding findings have shown about several people diagnosed with glioma malignancy in the same grade might react in contrast manners to radiotherapy management. Several grades III and IV gliomas react satisfactorily to radiotherapy. However, the relapse rate of high-grade glioma is still 
high and manifest opposition to therapy [6]. Therefore, management for this kind of primary brain malignancy has not been a satisfactory result [5].

While optimal management and multimodality approach such as magnetic resonance imaging (MRI), nuclear imaging, and fluid phase biopsy have been established, prognosis remains poor. Thus, investigating glioma on a molecular level that might contribute to the relapses and management resistance would be beneficial. Researchers have found that hypoxia is a significant microenvironmental factor in modulating malignant stem cells' self-renewal [7]. Also, it has also been observed that cancerous growth tend to withstand more against ionizing radiation through creating an environment that has a low oxygen concentration, thus creating the conclusion of radioprotective effect by hypoxia [8]. Therefore, a significant transcriptional factor that reacts well to oxygen-deprived surroundings can be taken into account of supporting the aforementioned problems, which are hypoxia-inducible factors (HIFs).

HIFs, such as HIF-1 $\alpha$ and HIF-2 $\alpha$, are important mediators in malignant hypoxia reaction, and high expression levels of hypoxia-inducible factors correlate with the concepts of metastasis, therapy opposition and reduced quality of prognosis in various form of cancerous growth $[8,9]$. HIF-2 $\alpha$ overexpression has been recorded to be connected with impoverished prognosis in malignant hepatoma, bowel cancer, skin cancer, ovarian cancer, and large cell pulmonary malignancy patients [10]. However, there are insufficient research data that has detected the expression of HIF-2 $\alpha$ in glioblastoma (grade IV glioma) and associate it with the patient outcome. The findings may help in the development of prognostic marker and effective therapeutic strategies for glioma patients. Therefore, this research was conducted to detect relative expression of HIF-2 $\alpha$ gene in the direction of glioma malignancy and its classification. This may result in the likelihood of making HIF-2 $\alpha$ to become an important prognostic marker on glioma patients subsequently and to answer whether there is a possibility of making HIF- $2 \alpha$ be a therapeutic target.

\section{METHODS}

\section{Samples}

This research was a cross-sectional study to observe the HIF- $2 \alpha$ gene expression on 20 human glioma tissues from 20 new cases of glioma patients who had signed informed consent at Cipto Mangunkusumo hospital and undertaken brain surgery within the period of 20142015. The tissues then were categorized based on their grade by doing a histopathological investigation, specifically Haematoxylin and Eosin (H\&E) staining, and those that did not match with the 2007 CNS WHO criteria were then ruled out. In total, there were 20 glioma tissues acquired which were comprised of variable grades (grade I-IV). Out of 20 glioma subjects, 2 individuals' normal brain tissues were obtained by resecting a different location from the glioma, which was subcortical. These normal brain tissues were used as a control to calculate the HIF- $2 \alpha$ relative expression by Livak formula [11].

\section{RNA extraction}

RNA was isolated utilizing Tripure Isolation Reagent (Roche). The $500 \mu \mathrm{L}$ of the solution was mixed with the 50-100 mg glioma samples that resulted in a homogeny characteristic. The homogenized solution was then stored at $-80^{\circ} \mathrm{C}$ before the solution was added with 100 $\mu \mathrm{L}$ of chloroform. This step was the initial way of the RNA separation, followed by the 15 minutes centrifugation of the mixed solution at $12,000 \mathrm{~g}$ at $4{ }^{\circ} \mathrm{C}$ to take supernatant containing RNA. Isopropanol was then added as much as $250 \mu \mathrm{L}$ to precipitate the RNA. Centrifugation was then performed at 12,000 g at $4^{\circ} \mathrm{C}$ for 10 minutes, and the precipitate was washed afterward with $75 \%$ ethanol. Another centrifugation was done at $7,500 \mathrm{~g}$ for 5 minutes, thus leaving the supernatants to be removed. The RNA pellet was left dry by opening the test tube and then diluted in $50 \mu \mathrm{L}$ of nuclease-free water. The RNA solution was then incubated at $55-60^{\circ} \mathrm{C}$ for 15 minutes. Following the incubation, the RNA was ready and stored at $-80^{\circ} \mathrm{C}$ when required [12].

\section{HIF-2 $\alpha$ gene amplification and quantification}

The amplification of HIF-2 $\alpha$ utilized SensiFAST SYBR $^{\circledR}$ No-ROX One-Step Kit (Bioline). The complete kit is composed of SensiFAST SYBR No-ROX One-Step mix, RiboSafe RNase Inhibitor, Reverse Transcriptase, and DEPC-H2O. SensiFAST SYBR ${ }^{\circledR}$ No-ROX One-Step kit has been mixed in advance with SYBR Green I Dye. The template of RNA total concentration was $100 \mathrm{ng}$ for quantitative Real-Time PCR [13]. Primers that were used could be seen in Table 1. The measurement of the gene expression was calculated as the relative expression using Livak method.

Table 1. Primer sequence

\begin{tabular}{cl}
\hline \multicolumn{1}{c}{ Primer } & \multicolumn{1}{c}{ Sequence } \\
\hline HIF-2 $\alpha[12]$ & Forward: 5'- ATAGCAGTGGCAAGGGGGCT- 3' \\
& Reverse: 5'- TCAGGGCTATTGGGCGTGGA-3' \\
18S Rrna [13] & $\begin{array}{l}\text { Forward: 5'AAACGGCTACCACATCCAAG-3' } \\
\text { Reverse: 5'-CCTCCAATGGATCCTCGTTA-3' }\end{array}$ \\
\hline
\end{tabular}




\section{Statistical analysis}

The assessment of HIF-2 $\alpha$ expression was performed utilizing the T-test analysis to decide the statistical proof on the differences between the mean values. However, due to an abnormal distribution found in the normality test, a non-parametric test (MannWhitney) was used for identifying the significance.

\section{RESULTS}

\section{Subject features}

A total of 20 glioma subjects was identified during this experiment: 13 samples were low grade and the rest were high-grade glioma malignancy subjects. Individuals were categorized into two, which were separated into $>50$ and $\leq 50$ years old classes. The agerelated assortment used the foundation of previous research that concludes as the most suitable sorting basis of age-groups, and 50-year-old was the finest cutoff point [14]. Table 2 displayed the number of subjects sorted into their features including subjects' age in years, glioma grading, and the histopathological appearance.

Table 2. Overall features of the whole glioma subjects

\begin{tabular}{ccl}
\hline \multicolumn{3}{c}{ Patient age } \\
\hline Group & N & $\%$ \\
$\leqq 50$ y.o & 17 & $75 \%$ \\
$>50$ y.o & 3 & $15 \%$ \\
\hline \multicolumn{3}{c}{ Glioma malignancy classification } \\
\hline Grade & $\mathbf{N}$ & $\%$ \\
Grade I & 2 & $10 \%$ \\
Grade II & 11 & $55 \%$ \\
Grade III & 3 & $15 \%$ \\
Grade IV & 4 & $20 \%$ \\
\hline \multicolumn{3}{c}{ Glioma pathological anatomy } \\
\hline Types & $\mathbf{N}$ & $\%$ \\
Oligoastrocytoma & 1 & $5 \%$ \\
Astrocytoma & 14 & $70 \%$ \\
Ganglioglioma & 1 & $5 \%$ \\
Glioblastoma Multiforme & 4 & $20 \%$ \\
\hline
\end{tabular}

\section{Glioma malignancy features}

The resolution of grading the subject's type of glioma employed the foundation of histological appearances. High-grade glioma was characterized by the appearance of anaplastic feature, high mitotic activity, and presence of necrotic area. In Figure 1, the malignant tumor is glioblastoma that shows high mitotic activity as can be seen by highly cellular structure and dense chromatin intensity. The cells also have an anaplastic appearance. The low-grade glioma is characterized by the cytological atypia. Pictures below displayed the results of microscopic examination of patients' glioma tissues, from the malignant and lower grade gliomas.
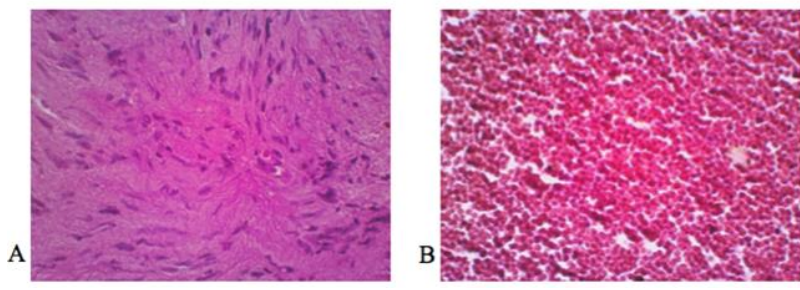

Figure 1. Histopathological examination results of two classifications of glioma colored with H\&E staining (both 400x magnification. (A) High-grade GBM type IV (B) Low-grade astrocytoma grade II (Magnification, 400x).

\section{HIF-2 $\alpha$ mRNA expression}

Table 3. Calculation results of the samples relative expression

Table 3a. High-grade glioma

\begin{tabular}{lc}
\hline Glioma type & Relative expression \\
\hline Glioblastoma multiforme grade IV & 0.9449811 \\
Astrocytoma grade III & 2.1774592 \\
Glioblastoma multiforme grade IV & 5.6340403 \\
Glioblastoma multiforme grade IV & 109.82376 \\
Astrocytoma grade III & 8.1980468 \\
Astrocytoma pilocytic grade III & 2.1514882 \\
Glioblastoma multiforme grade IV & 1.6031059 \\
\hline
\end{tabular}

Table 3b. Low-grade glioma

\begin{tabular}{lc}
\hline Glioma type & Relative expression \\
\hline Astrocytoma grade II & 8.2597006 \\
Oligoastrocytoma grade II & 16.231264 \\
Astrocytoma grade II & 4.2999386 \\
Astrocytoma grade II & 3.5399357 \\
Astrocytoma grade II & 8.9508882 \\
Astrocytoma pilocytic grade II & 0.8879269 \\
Astrocytoma fibrillary grade II & 0.2868066 \\
Astrocytoma grade II & 1.1788094 \\
Ganglioglioma grade I & 0.484175 \\
Astrocytoma grade II & 1.7412652 \\
Astrocytoma grade II & 2.6482929 \\
Astrocytoma grade II & 23.435106 \\
Astrocytoma diffuse grade II & 2.0042064 \\
\hline
\end{tabular}


The cycle threshold numbers were taken from Real Time quantitative PCR experiment on the HIF-2 $\alpha$ expression, utilizing the Applied Biosystem software. Furthermore, the cycle threshold numbers were applied for the relative expression computation. The relative expression was calculated using the cycle threshold values. Table 3 showed the results regarding the relative expression of HIF- $2 \alpha$.

Considering the results from Table 3, the conclusion regarding an observed common tendency that HIF-2 $\alpha$ is present at a higher degree in high-grade glioma, rather than grade I and grade II glioma can be taken. The attained average of HIF- $2 \alpha$ relative expression in grade III and grade IV glioma was $18.647554(n=7)$, whereas in the lower types the expression value was 5.688332 ( $n=13)$, indicating the likelihood of HIF-2 $\alpha$ overexpression in higher grade gliomas. Figure 2 described the distribution of each sample in this experiment and showed an extraordinarily high disparity of HIF-2 $\alpha$ relative expression in a certain sample that contrasted with grade I and grade II glioma, which was glioblastoma multiforme type IV. Nonparametric test using the Mann-Whitney method displayed that there was no significant difference between the two population of high grade and lowgrade glioma in the expression of HIF- $2 \alpha(p>0.05)$.

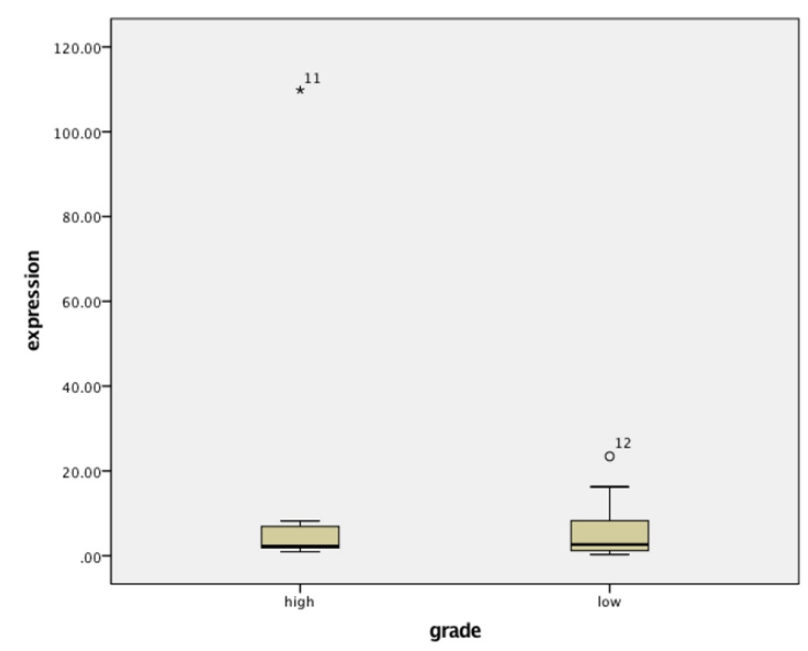

Figure 2. HIF-2 $\alpha$ relative expression results distribution for both category of brain gliomas.

\section{DISCUSSION}

According to the results of, a total of 20 glioma samples, taken from new cases of glioma patients, have all expressed HIF-2 $\alpha$ in both low-grade and high-grade gliomas. It has been a known theory that one of the key features of a cancerous growth is that it contains areas of hypoxic environment, which are also often observed around necrotic zones. This phenomenon is mainly caused by the overwhelming proliferation of cancerous cells, thus explained the significant difference with the surrounding normal cells, of which the malignant ones required more oxygen to be used. Hypoxia Inducible Factors (HIFs) are substantial proteins that act in stress feedback to oxygen depressed situation, consequently making the cells to stimulate the response pathway involving gene expression programs [15]. Hu et al. [16] experiments resulted in the expression of HIF-2 $\alpha$ in renal cell carcinoma cells that revealed a mutation in VHL gene, which encodes the von Hippel-Lindau tumor suppressor protein. In addition, other researchers also have observed HIF-2 $\alpha$ expression in both renal cell carcinoma cells and colon carcinoma cells $[17,18]$. These outcomes confirm the presence of HIF-2 $\alpha$ expression in a wide range of malignancy types and may function as a diagnostic marker.

HIF- $2 \alpha$ quantification results are exhibited in Table 3 and show an elevated average of expression in highgrade gliomas compared to the lower types. The mean HIF-2 $\alpha$ relative expression in grade III and IV category was 18.647554 from a total of 7 samples, while the lowgrade glioma yields an average of 5.688332 from 13 samples. This correlates with a previous study by $\mathrm{Hu}$ et al. [19] that detected an elevated number of differentially expressed genes (including EGFR gene that is modulated by HIF-2 $\alpha$ ) in accordance with the increasing glioma grade, of which, in their research, the greatest amount was identified in grade IV glioma. The expression results gave thoughts to the effect of the hypoxic situation on the brain glioma cells, which issued those hypoxia-related genes, may have also been concerned with the outcome of glioma by stimulating the hypoxia feedback mechanism. Considering the small amount of subject with 20 glioma samples, evaluation of associated hypoxic genes expression, which in this case is HIF- $2 \alpha$, in glioma patients might possess prospective prognostic merit. This has also been proposed by El Guerrab et al. [20] in their experiment on hypoxiaassociated genes expression on breast malignancy.

Nevertheless, it can be noticed that some glioma subjects expressed various mean relative expression of both categories of glioma. An example can be seen in HIF-2 $\alpha$ relative expression of Astrocytoma grade II, which was 23.435106 and was greater than the mean expression of grade III and grade IV glioma combined, yet it was smaller than the highest expression recorded in this experiment, which was of the glioblastoma multiforme grade IV with the relative expression value of 109.876. In other hands, a glioblastoma multiforme grade IV sample with 0.9449811 expression level had a reduced state of expression compared to the most lowgrade glioma subjects, yet it was still greater than the smallest expression recorded in this experiment, which was of ganglioglioma grade I with expression value of 0.484175 . In spite of the clinical trend, which a greater HIF-2 $\alpha$ is expressed with the increasing grade of glioma, 
these inconstant details that were obtained might have affected the statistically inconsequential result. A probability that may explain the aforementioned results was pluripotency that is involved during the differentiation of the glioma cells. HIF- $2 \alpha$ has been spotted to stimulate the important genes associated in initiating the pluripotent state, comprising Oct4 and also c-Myc in previous researches by Covello et al [22]. They concluded that HIF-2 $\alpha$ can modulate glioma stem cell activity and differentiation by stimulating the Oct-4 gene, which successively will give benefit to HIF- $2 \alpha$ activity on advancing the cancerous activity [21]. This additional pluripotent ability of HIF- $2 \alpha$ also generates the idea that some grade I and II glioma have a greater number of relative expressions than the higher grade samples, as can be explained by further genetic pathways that resulted in amplification of the tumor cells. Thus, it can be hypothesized that some particular grade I and II gliomas, which have a comparatively greater number of HIF- $2 \alpha$ relative expression, possess the probability of progressing into high-grade glioma and consequently poor prognosis, as glioblastoma multiforme may occur de novo and also from an alteration of low-grade gliomas.

Some grade III and grade IV glioma samples that expressed relatively low HIF- $2 \alpha$ levels also might indicate a better prognosis towards the patients. Some publications have stated that HIFs, including HIF-2 $\alpha$, correlate with the perception of chemotherapy resistance in several other cancers such as liver [22], lung [23], renal [24], and colorectal [25] cancer. According to those papers, HIF-2 is responsible for allowing a vigorous proliferation of the cancerous cells that further impede the drug's efficacy. Relating those findings to the results of this experiment, it may be concluded that those glioma samples with low HIF-2 $\alpha$ expression might produce a reduced state of resistance towards radiotherapy compared to the other subjects with higher HIF-2 $\alpha$ expression. However, to reveal more comprehensive results of HIF- $2 \alpha$ as a prognostic marker in brain glioma patients, a greater number of subjects are required. It is also suggested to perform further cohort experiment to identify the connection of therapy initiation and the survival rate of the individuals.

Lastly, glioma malignancy is characterized as heterogeneous which might be promoted by cancer stem cells diverse allocation and that the development of glioma could result from a particular reaction amidst the microenvironment (in this case hypoxia) and the certain glial tissue [26]. This perspective of molecular heterogeneity by Tchoghandjian et al. [26] gives the thought of why the HIF-2 $\alpha$ relative expression in some high-grade glioma was not exceptionally great, as there might be a probability which the section of the cerebrum obtained was concerned not malignant enough whereas that certain individual was deemed as having grade III or grade IV glioma. This also brought up the classification used in this research, which was 2007 CNS WHO that categorized glioma based on microscopic appearances in histopathology examination (H\&E staining). The newer version, 2016 CNS WHO, was a fundamental advancement over the previous one as it considers molecular framework [4]. It is believed to be the starting point for such progress for the next WHO classification of central nervous system tumors and further aid many study aspects of the medical world primarily in alleviating individuals' lives with glioma. Future experiments hence are advised to refer to the newer version of the classification as it is likely to diminish the mRNA expression variability of the glioma samples.

\section{CONCLUSION}

The results taken from this research exhibited a HIF- $2 \alpha$ overexpression trend in the high-grade glioma contrasted to the low types, nevertheless the relative expression distinction has not achieved significant status.

\section{DECLARATIONS}

\section{Competing of Interest}

The authors declare no competing interests in this study

\section{Acknowledgment}

The authors wish to thank the Molecular Biology and Proteomics Core Facilities (MBPCF) Indonesia Medical Education and Research Institute (IMERI), Faculty of Medicine Universitas Indonesia for providing the qPCR instrument used in the study.

\section{REFERENCES}

1. Ahmed R, Oborski MJ, Hwang M, Lieberman FS, Mountz JM. Malignant gliomas: current perspectives in diagnosis, treatment, and early response assessment using advanced quantitative imaging methods. Cancer Manage Res. 2014;6:149.

2. McFaline-Figueroa JR, Lee EQ. Brain tumors. Am J Med. 2018;131(8):874-82.

3. Ostrom QT, Bauchet L, Davis FG, Deltour I, Fisher JL, Langer $\mathrm{CE}$, et al. The epidemiology of glioma in adults: a "state of the science" review. Neuro Oncol. 2014;16(7):896-913.

4. Louis DN, Perry A, Reifenberger G, Von Deimling A, Figarella-Branger D, Cavenee WK, et al. The 2016 World Health Organization classification of tumors of the central nervous system: a summary. Acta neuropathol. 2016;131(6):803-20.

5. Munthe S, Petterson SA, Dahlrot RH, Poulsen FR, Hansen S, Kristensen BW. Glioma cells in the tumor periphery have a stem cell phenotype. PloS one. 2016;11(5):e0155106. 
6. Aman RA. Identification on predictive factors of the radiosensitivity of glial cell tumour: A review on angiogenesis, cell proliferation and apoptosis as behaviours of biologic tumour. [Dissertation]. Jakarta: Faculty of Medicine Universitas Indonesia; 2008.

7. Li Z, Rich JN. Hypoxia and hypoxia inducible factors in cancer stem cell maintenance. In: Diverse effects of hypoxia on tumor progression. Springer Berlin Heidelberg. 2010:p. 21-30.

8. Rockwell S, Dobrucki IT, Kim EY, Marrison ST, Vu VT. Hypoxia and radiation therapy: past history, ongoing research, and future promise. Curr $\mathrm{Mol}$ Med. 2009;9(4):442-58.

9. McNamee EN, Johnson DK, Homann D, Clambey ET. Hypoxia and hypoxia-inducible factors as regulators of $\mathrm{T}$ cell development, differentiation, and function. Immunol Res. 2013;55(1-3):58-70.

10. Roig EM, Yaromina A, Houben R, Groot AJ, Dubois L, Vooijs M. Prognostic Role of Hypoxia-Inducible Factor-2 $\alpha$ Tumor Cell Expression in Cancer Patients: A Meta-Analysis. Frontiers in Oncology. 2018;8.

11. Livak K, Schmittgen T. Analysis of relative gene expression data using real-time quantitative PCR and the 2- $\triangle \Delta C T$ method. Methods. 2001;25:402-8.

12. Hamid F, Hardiany N, Hikmah F, Ichwan S. Relative expression of C-MYC mRNA in human glioma cells related to the degree of malignancy. eJournal Kedokt Indones. 2017;5(2):85-90.

13. Paramita R. Peran hypoxia inducible factor (HIF) terhadap ketahanan hidup sel kanker payudara manusia T47D melalui pengaturan sitokrom-c dan surviving. 2014; (in Dissertation).

14. Chen J, Zhou C, Lin Z. The influence of different classification standards of age groups on prognosis in high-grade hemispheric glioma patients. J Neurol Sci. 2015;356:148-52.

15. Majmundar AJ, Wong WJ, Simon MC. Hypoxiainducible factors and the response to hypoxic stress. Molecular cell. 2010 Oct 22;40(2):294-309.

16. Hu CJ, Wang LY, Chodosh LA, Keith B, Simon MC. Differential roles of hypoxia-inducible factor $1 \alpha$ (HIF- $1 \alpha$ ) and HIF-2 $\alpha$ in hypoxic gene regulation. Mol Cell Biol. 2003;23(24):9361-74.

17. Han S, Huang $T$, Li W, Liu S, Yang $W$, Shi $Q$, et al. Association between hypoxia-inducible factor- $2 \alpha$ (HIF-2 $\alpha$ ) expression and colorectal cancer and its prognostic role: a systematic analysis. Cell Physiol
Biochem. 2018;48:516-27.

18. Schodel J, Grampp S, Maher ER, Moch H, Ratcliffe PJ, Russo P, et al. Hypoxia, hypoxia-inducible transcription factors, and renal cancer. Eur Urol. 2016;69(4):646-57.

19. Hu G, Wei B, Wang L, Wang L, Kong D, Jin Y, et al. Analysis of gene expression profiles associated with glioma progression. Mol Med Rep. 2015;12(2):1884-90.

20. El Guerrab A, Cayre A, Kwiatkowski F, Privat M, Rossignol JM, Rossignol $F$, et al. Quantification of hypoxia-related gene expression as a potential approach for clinical outcome prediction in breast cancer. PloS one. 2017;12(4):e0175960.

21. He C, Sun XP, Qiao H, Jiang X, Wang D, Jin X, Dong X, Wang J, Jiang $H$, Sun $X$. Downregulating hypoxiainducible factor- $2 \alpha$ improves the efficacy of doxorubicin in the treatment of hepatocellular carcinoma. Cancer science. 2012 Mar;103(3):52834.

22. Covello KL, Kehler J, Yu H, Gordan JD, Arsham AM, $\mathrm{Hu} \mathrm{CJ}$, et al. HIF-2 $\alpha$ regulates Oct-4: effects of hypoxia on stem cell function, embryonic development, and tumor growth. Genes Dev. 2006;20(5):557-70.

23. Stoleriu MG, Steger $V$, Mustafi $M$, Michaelis $M$, Cinatl J, Schneider W, Nolte A, Kurz J, Wendel HP, Schlensak C, Walker T. A new strategy in the treatment of chemoresistant lung adenocarcinoma via specific siRNA transfection of SRF, E2F1, Survivin, HIF and STAT3. Eur J Cardiothorac Surg. 2014;46(5):877-86.

24. Selvarajah J, Nathawat K, Moumen A, Ashcroft M, Carroll VA. Chemotherapy-mediated p53dependent DNA damage response in clear cell renal cell carcinoma: role of the mTORC1/2 and hypoxiainducible factor pathways. Cell Death Dis. 2013;4(10):e865.

25. Jin $F$, Ji $H$, Jia $C$, Brockmeier $U$, Hermann DM, Metzen E, Zhu Y, Chi B. Synergistic antitumor effects of endostar in combination with oxaliplatin via inhibition of HIF and CXCR4 in the colorectal cell line SW1116. PLoS One. 2012;7(10):e47161.

26. Tchoghandjian A, Koh MY, Taieb D, Ganaha S, Powis G, Bialecki E, Graziani N, Figarella-Branger D, Metellus P. Hypoxia-associated factor expression in low-grade and anaplastic gliomas: a marker of pooroutcome. Oncotarget. 2016. 